Article

\title{
Cross-Selectivity Enhancement of Poly(vinylidene fluoride-hexafluoropropylene)-Based Sensor Arrays for Detecting Acetone and Ethanol
}

\author{
Ali Daneshkhah ${ }^{1,2}$, Sudhir Shrestha ${ }^{1,2,+}$, Amanda Siegel ${ }^{2}$, Kody Varahramyan ${ }^{1,2}$ \\ and Mangilal Agarwal 2,3,* \\ 1 Department of Electrical and Computer Engineering, Indiana University-Purdue University \\ Indianapolis (IUPUI), Indianapolis, IN 46202, USA; alidane@umail.iu.edu (A.D.); \\ shrests2@miamioh.edu (S.S.); kvarahra@iupui.edu (K.V.) \\ 2 Integrated Nanosystems Development Institute (INDI), Indiana University-Purdue University \\ Indianapolis (IUPUI), Indianapolis, IN 46202, USA; apsiegel@iupui.edu \\ 3 Department of Mechanical Engineering, Indiana University-Purdue University Indianapolis (IUPUI), \\ Indianapolis, IN 46202, USA \\ * Correspondence: agarwal@iupui.edu; Tel.: +1-317-278-9792 \\ + Present Address: Department of Electrical and Computer Engineering, College of Engineering and \\ Computing, Miami University, Oxford, OH 45056, USA
}

Academic Editor: W. Rudolf Seitz

Received: 14 November 2016; Accepted: 6 March 2017; Published: 15 March 2017

\begin{abstract}
Two methods for cross-selectivity enhancement of porous poly(vinylidene fluoride-hexafluoropropylene) (PVDF-HFP)/carbon black (CB) composite-based resistive sensors are provided. The sensors are tested with acetone and ethanol in the presence of humid air. Cross-selectivity is enhanced using two different methods to modify the basic response of the PVDF-HFP/CB sensing platform. In method I, the adsorption properties of PVDF-HFP/CB are altered by adding a polyethylene oxide (PEO) layer or by treating with infrared (IR). In method II, the effects of the interaction of acetone and ethanol are enhanced by adding diethylene carbonate (DEC) or PEO dispersed in DEC (PEO/DEC) to the film. The results suggest the approaches used in method I alter the composite ability to adsorb acetone and ethanol, while in method II, they alter the transduction characteristics of the composite. Using these approaches, sensor relative response to acetone was increased by $89 \%$ compared with the PVDF-HFP/CB untreated film, whereas sensor relative response to ethanol could be decreased by $57 \%$ or increased by $197 \%$. Not only do these results demonstrate facile methods for increasing sensitivity of PVDF-HFP/CB film, used in parallel they demonstrate a roadmap for enhancing system cross-selectivity that can be applied to separate units on an array. Fabrication methods, experimental procedures and results are presented and discussed.
\end{abstract}

Keywords: acetone sensor; ethanol sensor; volatile organic compounds; PVDF-HFP/carbon black composite; low water sensitivity

\section{Introduction}

Volatile Organic Compounds (VOCs) are present in the air in varying concentrations. As chronic exposure to some VOCs can cause ill effects to human health, it is important that reliable detection methods be developed and utilized. Cross-selective sensors can be applied to screen for VOCs in numerous applications. Resistive sensor arrays for detecting organic compounds are primarily developed on interdigitated electrodes (IDEs) of gold over glass, silicon oxide, and polymer substrates [1,2]. The adsorption of VOCs on the surface of sensing materials changes the resistance of the films. Sensor arrays consisting of functionalized carbon nanotubes (CNTs), graphene, conductive polymers, 
carbon black, metal oxide, gold nanoparticles, and conducting polymer composites have been studied extensively for their ability to detect organic compounds [1-6]. The variance in single wall carbon nanotube (SWNT) chiral distributions makes it difficult to fabricate sensors reproducibly [5]. CNT conductance is sensitive to temperature, humidity and air flow speed [6]. In addition, a relatively high response to oxygen, carbon dioxide and water vapor present in the environment can be major drawbacks for CNT- and graphene-based VOC sensors [7,8]. Response to water vapor and dependency on temperature are undesirable features of metal oxide and monolayer-capped gold nanoparticles [2,9-12]. Sensor degradation is a concern for monolayer-capped gold nanoparticle-based sensors, and sensors fabricated from conducting polymers such as polypyrrole (PPy) and polyaniline (PANI) [13-15]. Composites of polymers with conductive fillers offer good stability and have widely been used for the development of electronic noses [16-18]. These sensors comprise a polymer that senses the gas, and a conducting filler such as CB to increase conductivity. Swelling of the polymer due to interactions with VOCs increases the separation between the conducting particles which in turn increases the film resistivity $[19,20]$. A thick film can be developed over the IDE via a drop-casting method [16,17]. In order to change the cross selectivity of the sensors in an array of sensors, different combinations of polymers are used $[16,18]$. Reproducible development of multiple thin films on a single substrate is a challenging task. These challenges have drawn much attention and methods such as automatic thin film transferring are investigated [21,22]. One simple solution is to change the selectivity of the thin film after sensor development. PVDF-HFP is well known for its applications in piezoelectric devices and batteries. Its high stability and hydrophobicity with low degradation and good resistivity against many chemicals make it a good candidate for making selective resistor based gas sensors [2]. Fabrication of a thin film PVDF-HFP/CB results in the development of reliable sensors to detect VOCs while rejecting water vapor [2]. However, these sensors currently lack the cross-selectivity needed for them to be effective in a sensor array. Detecting VOCs with specificity will require an array of cross-selective sensors $[2,16,18]$. Here we present methods of enhancing the cross-selectivity of PVDF-HFP-based sensors seeded with CB in a single thin film. PVDF-HFP/CB composite can adopt three crystalline structures, $\alpha, \beta$, and $\gamma$ [23]. The different polymeric composite structures adsorb VOCs differently. Effectively, the $\beta$ and $\gamma$ structures are more polar, while the $\alpha$ one is more symmetrical and nonpolar [23]. In this paper, we report methods of enhancing cross-selectivity of porous PVDF-HFP/CB-based sensors by varying the surface and structural properties of the film.

One hallmark of cross-selectivity is how a sensor responds to different volatile organic compounds. For this study, we will demonstrate the results of cross-selective enhancements utilizing a polar compound, ethanol, and a nonpolar compound, acetone. Sensitivity of the PVDF-HFP/CB sensors described herein are similar to those reported in other studies as evidenced by examples shown in Table 1.

Table 1. Reported percentage of resistance change in response to ethanol and acetone for resistor based sensors at room temperature in different studies.

\begin{tabular}{|c|c|c|}
\hline Material & Acetone & Ethanol \\
\hline Poly(4-vinylphenol)/CB & $4.2 \%(49,000$ ppm) [24] & $2.3 \%(10,000 \mathrm{ppm})[24]$ \\
\hline $\mathrm{PMMA} / \mathrm{f}-\mathrm{CNT}$ & $30 \%(55,000 \mathrm{ppm}) *[25]$ & $1.7 \%(5000 \mathrm{ppm}) *[26]$ \\
\hline Iso-butyl methyl ketone/CNT & Not available & $1.25 \%$ (1000 ppm) [27] \\
\hline PDLC/CNT & $4 \%(1800 \mathrm{ppm}) *[28]$ & Not available \\
\hline Network of CNT & $1 \%(3200 \mathrm{ppm}) *[29]$ & $11.3 \%(77,000 \mathrm{ppm}) *[30]$ \\
\hline Network of oxidized CNT & $3.3 \%(3200 \mathrm{ppm}) *[29]$ & $4.2 \%(5000 \mathrm{ppm}) *[31]$ \\
\hline Organic thiol capped GNP & $0.5 \%(500 \mathrm{ppm}) *[13]$ & $1.15 \%(1500 \mathrm{ppm})[32]$ \\
\hline
\end{tabular}

\section{Materials and Methods}

CB (Black Pearl 2000) was obtained from Cabot Corporation (Boston, MA, USA). PVDF-HFP (FLEX 2801 PVDF), obtained from Arkema Group Kynar (Colombes, France) is comprised of PVDF 
with around 3.5\%-7.5\% HFP. Diethylene carbonate (DEC) was purchased from Novolyte Technologies (Zachary, LA, USA). 1-Methyl-2-pyrrolidinone (NMP) anhydrous, glycerol anhydrous and polyethylene oxide (PEO) (average Mv 4,000,000), were purchased from Sigma Aldrich (St. Louis, MO, USA). The composite of PVDF-HFP/CB/glycerol $(20: 1: 4 w / w)$ is synthesized in NMP. The sensors were fabricated using IDEs of gold ( $25 \mu \mathrm{m}$ spacing) over silicon oxide. A standard photolithography process was used to fabricate the IDEs [2]. Spin-coating method was used to cast a thin film of synthesized materials slurry over the IDEs. The film thickness is estimated to be less than $4 \mu \mathrm{m}$. Next, the film was dried slowly in ambient temperature followed by washing with water to remove the glycerol from the composite. The PVDF-HFP and CB form a conducting porous film. To better understand the contribution of CB in PVDF-HFP/CB sensors, CB only sensors were also fabricated via drop-casting of $\mathrm{CB}$ in NMP directly onto the IDE.

PVDF-HFP swells due to interactions with VOCs, and this increases the separation between the conducting particles, thereby increasing film resistivity. There are two major factors that determine a sensor's ability to detect a specific VOC. First, the ability of the sensing material to adsorb the VOC (defined as adsorption efficiency) and, second, the effects of interactions of adsorbed compounds with the composite in changing the film resistivity (defined as transduction efficiency). Enhancement in adsorption efficiency leads to more interaction between the VOC and the film which increases the swelling of the film and thus the film resistivity. Enhancement in transduction efficiency causes more resistance change with the adsorbed VOCs which increases the sensitivity. These factors have been utilized in the presented two methods (method I and method II) to enhance the cross-selectivity of PVDF-HFP/CB composite films. Method I seeks to alter adsorption properties (adsorption efficiency) and method II seeks to alter the transduction properties (transduction efficiency). In method I, a thin PEO layer was cast over the film, or the film was treated with an IR lamp. The addition of PEO layer enhances ethanol adsorption while an IR treatment reduces it. In method II, transduction efficiency was improved for both ethanol and acetone through the addition of DEC or PEO/DEC to the film. The addition of DEC increased the sensitivity to both acetone and ethanol, whereas the addition of PEO/DEC skewed it toward ethanol. These processes are further described in Figure 1, shown below.

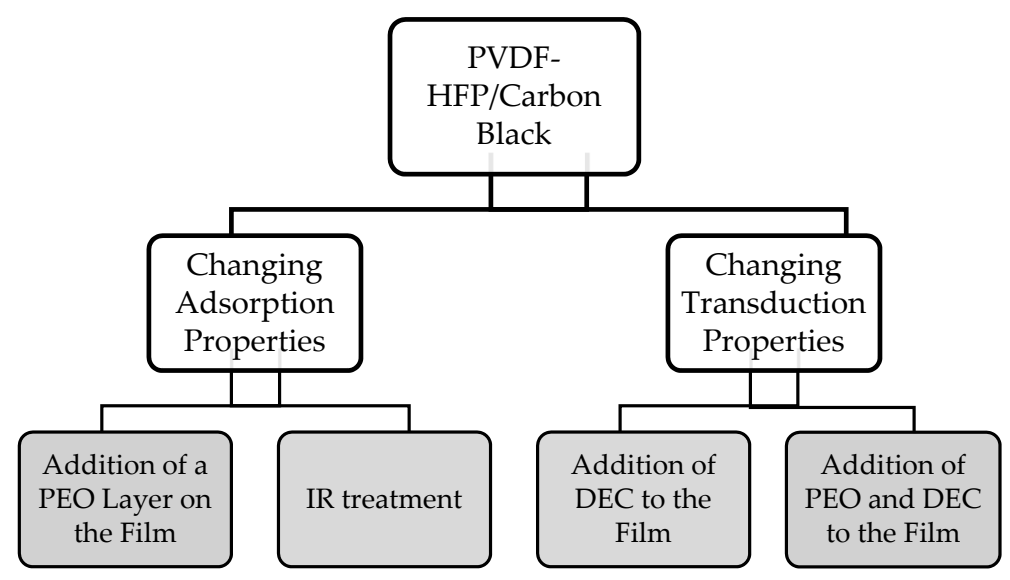

Figure 1. Presented methods to enhance cross selectivity of the porous thin PVDF-HFP/CB film.

\subsection{Method I}

The enhancement in the composite ability to adsorb VOCs causes more VOCs to interact with the composite, thereby increasing adsorption efficiency by increasing the resistance change in response to VOCs. Method I uses two approaches to alter the ability of the PVDF-HFP/CB film to adsorb and capture VOCs. These two approaches are addition of a PEO layer on the film and IR treatment. The two approaches and their potential to alter adsorption ability of the composite are unpacked. 


\subsubsection{Addition of a PEO Layer on the Film}

The slow evaporation of the film causes formation of microscale pores in the PVDF-HFP/CB composite. These pores can be filled with polymers to attract VOCs. In the presented work, a PEO layer was added to the composite film by drop-casting a solution of high molecular weight PEO. A water bath was then used to wash away the bulk of PEO from the composite and leave a very thin layer. A quartz crystal microbalance (QCM) experiment before and after the addition of PEO layer was used to confirm the formation of a thin PEO layer on the PVDF-HFP/CB. PEO strongly attracts VOCs such as ethanol and acetone [33-35]. Thus the fabricated thin PEO layer on the PVDF-HFP/CB composite adsorbs ethanol and acetone differently than PVDF-HFP/CB alone.

\subsubsection{IR Treatment of the Film}

PVDF-HFP has a property whereby it can offer either a more polar crystalline structure ( $\beta$-phase and $\gamma$-phase), or less polar crystal structure ( $\alpha$-phase) $[2,23,36]$. The IR treatment of PVDF-HFP in the presence of CB particles has been investigated. Sensors were exposed to a $200 \mathrm{~W}$ IR lamp at a distance of $10 \mathrm{~cm}$ for one hour immediately after the material was cast on them. A mask was used to protect half of the sensors from IR radiation. Treatment of PVDF-HFP/CB with IR alters the crystal structure of the film. The change in PVDF-HFP/CB crystalline structure and polarity alters the composite's tendency to adsorb the more polar ethanol and less polar acetone.

\subsection{Method II}

Enhancement in transduction efficiency increases sensor's response to a fixed amount of adsorbed VOCs. Two approaches were used in method II to enhance the transduction properties of the composite: first, addition of DEC to the film and second, addition of PEO and DEC to the film. The two approaches and their potential effects in enhancement of cross selectivity are described.

\subsubsection{Addition of DEC to the Film}

DEC was drop-cast on the surface of the PVDF-HFP/CB film. PVDF-HFP has a slight interaction with DEC and is, thus, considered as a gelation solvent [37]. DEC can wash away the CB clumps or interact with the small amount of oxygen groups on $C B$. This causes the $C B$ to disperse with higher uniformity throughout the film. Enhancement of CB's distribution in a composite has been reported elsewhere as a means of altering the efficacy of sensor transduction and conducting properties [20].

\subsubsection{Addition of PEO and DEC to the Film}

PEO was added to the DEC and sonicated for $4 \mathrm{~h}$. PEO/DEC was drop-cast on the surface of the PVDF-HFP/CB film. The use of PEO and DEC may act to transform CB particles into a PEO/CB composite. Since PEO is nonconductive, the resistivity of a $\mathrm{PEO} / \mathrm{CB}$ composite would be higher than $\mathrm{CB}$ without $\mathrm{PEO}$. This has been supported by resistance measurements across the film before and after drop-casting of PEO/DEC. Furthermore, addition of PEO to the composite alters the sensor transduction, as PEO swells differently in the presence of acetone or ethanol than PVDF-HFP does.

\subsection{Material Characterization}

A Nicolet iS10 FTIR spectrometer (Thermo Scientific, Waltham, MA, USA) was used to conduct FTIR experiments on films fabricated on a potassium bromide $(\mathrm{KBr})$ disc $(25 \mathrm{~mm} \times 4 \mathrm{~mm})$. Omnic software was used to estimate the FTIR peaks. An X-ray diffraction (XRD) model D8 Discover instrument with a Lynxeye XE detector (Bruker, Billerica, MA, USA) was used for further analysis of the PVDF-HFP crystal structure. A JSM-7800F field emission scanning electron microscope (JEOL USA, Peabody, MA, USA) was used to provide images and investigate the morphological properties of the PVDF-HFP/CB and pure CB on interdigitated electrodes. An EZ digital FC-7015U $100 \mathrm{MHz}$ universal counter (EZ Digital, Anyang-si, Gyeonggi-do, Korea) with a $9 \mathrm{MHz}$ QCM lever oscillator was used to measure 
frequency change of modified QCM. Acetone and ethanol concentrations were quantified using a solid phase microextraction (SPME) fiber (divinylbenzene/carboxen/polydimethylsiloxane, Supelco, Bellefonte, PA, USA) of collected samples analyzed by gas chromatography/mass spectrometry (Agilent 7890A/5975C, Santa Clara, CA, USA).

\subsection{Sensor Experimental Set-Up}

The experimental setup used is illustrated in Figure 2. The intended application of the sensors is for detecting VOCs in workplace environments. This is demonstrated using acetone and ethanol. The occupational safety and health administration (OSHA) endorses a humidity of $20 \%-60 \%$ for workplace [38]. Thus, humidified air ( $80 \%$ nitrogen, $19 \%$ oxygen, $<1 \%$ carbon dioxide, $45 \%$ relative humidity), was used as a carrier gas to test the sensors. Purified air (Air Medipure brand, grade USP, Praxair, Danbury, CT, USA) at a fixed flow rate was bubbled through liquid acetone/ethanol in a flask. The resulting gas was diluted with pure air. Air is also bubbled through water in another flask to obtain a constant $45 \%$ RH humidity. The gasses are homogenized in the gas stabilizer. The concentration of VOCs and the humidity level is altered by controlling the flow of air (using mass flow controllers, MFC1, MFC2 and MFC3). The concentration of acetone/ethanol for given experimental conditions and flow rate were determined through gas chromatography/mass spectroscopy (GC/MS). The mixture of acetone/ethanol and air coming out of the flask was passed through a vial cooled by dry ice. The acetone/ethanol trapped inside the vial was adsorbed onto a SPME fiber and transferred to GC/MS for analysis. The samples under analysis were placed inside the test chamber and the desired measurements were taken. $R_{V O C}$ denotes a resistance measurement taken in the presence of ethanol or acetone, and $R_{\text {air }}$ represents a resistance measurement taken in the absence of ethanol/acetone. The experiments were conducted at $22 \pm 1{ }^{\circ} \mathrm{C}$. Concentrations of acetone and ethanol are reported in parts per million (ppm).

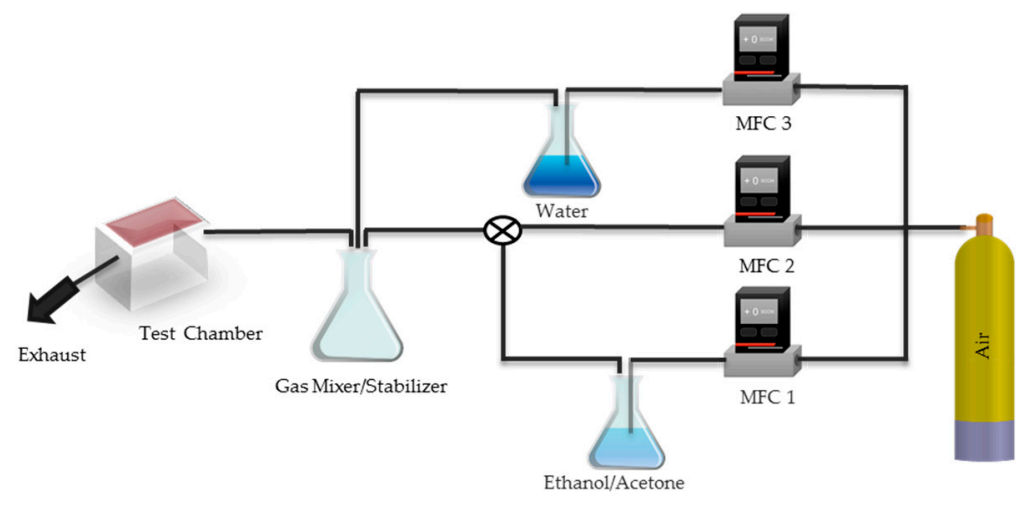

Figure 2. Schematic of sensor testing setup.

\section{Material Characterization Results and Discussion}

The fabricated PVDF-HFP and PVDF-HFP/CB composites (with and without DEC and with and without IR treatment) were characterized using FTIR to provide information about the composite character bands, orientation of specific functional groups, polarity and the different crystalline structure of the polymer in the composite. XRD analysis was used to identify the semi-crystalline forms and scanning electron microscopy (SEM) analysis provided data about the morphology of the different PVDF-HFP/CB composites.

\subsection{FTIR Analysis of IR Treatment and DEC Addition}

PVDF presents three primary crystalline forms. The $\alpha$-phase offers a non-polar trans-gauche-trans-gauche' conformation (TGTG') [23]. The $\beta$-phase, which is more polar, assumes 
a distorted planar zig-zag. The polarity is caused by the fluorine atoms (filled) locating opposite to the hydrogen atoms (unfilled) in the crystal structure. The $\gamma$-phase assumes a polar unit cell intermediate between the helical $\alpha$ and zig-zag $\beta$ structure [23]. PVDF with added HFP (HFP ratio of $3.5 \%-7.5 \%$ ) also assumes these structures (Figure 3) [39]. Polymorphism of PVDF-HFP can be used to control the adsorption properties of the polymer composites. FTIR analysis was conducted for PVDF-HFP and PVDF-HFP/CB in the conditions to evaluate the effects of IR-treatment and addition of DEC to the film. Peaks reported in this section with suggested structural features noted in parenthesis (suggested features are within 1 or $2 \mathrm{~cm}^{-1}$ of peaks reported elsewhere for PVDF or PVDF-HFP [39-52]).

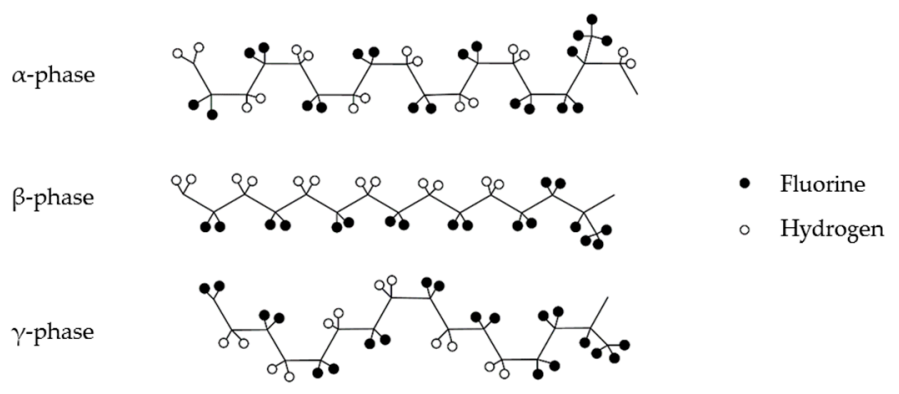

Figure 3. The $\alpha$-phase, $\beta$-phase, $\gamma$-phase crystal structures of PVDF-HFP demonstrating the $\alpha$-phase is far less polar than the $\beta$-phase. Ratio of PVDF:HFP 15:1 (HFP structure on the right).

\subsubsection{FTIR Analysis of PVDF-HFP and PVDF-HFP/CB}

FTIR was undertaken for PVDF-HFP alone and PVDF-HFP/CB (Figure 4). The extensive changes to the PVDF-HFP FTIR peaks on addition of CB demonstrate the crystal structure of the polymer undergoes structural changes in formation of the composite. Peaks in PVDF-HFP at $511 \mathrm{~cm}^{-1}\left(\mathrm{CF}_{2}[40]\right.$, $\beta$-phase [41]), $658 \mathrm{~cm}^{-1}, 838 \mathrm{~cm}^{-1}\left(\mathrm{CH}_{2}\right.$ rocking [33], $\beta$-phase [43]), $880 \mathrm{~cm}^{-1}\left(\mathrm{CF}_{2}\right.$ stretching [42], $\alpha$-phase [41], $1073 \mathrm{~cm}^{-1}$ (out of plan deformation [44]), $1178 \mathrm{~cm}^{-1}$ (asymmetric stretching of C-F bond [45]), $1231 \mathrm{~cm}^{-1}$ ( $\gamma$-phase [46]), $1404 \mathrm{~cm}^{-1}\left(\mathrm{CH}_{2}\right.$ wagging [47]), are shifted in PVDF-HFP/CB to $509 \mathrm{~cm}^{-1}, 656 \mathrm{~cm}^{-1}, 835 \mathrm{~cm}^{-1}$ (gamma phase [46]), $876 \mathrm{~cm}^{-1}, 1069 \mathrm{~cm}^{-1}, 1167 \mathrm{~cm}^{-1}, 1229 \mathrm{~cm}^{-1}$, $1399 \mathrm{~cm}^{-1}$. The peak at $1680 \mathrm{~cm}^{-1}$ (symmetrical stretching vibration of $C=C$ [48]) has disappeared but new peaks are observed due to insertion of $\mathrm{CB}$ and formation of the composite. New peaks in PVDF-HFP/CB are detected at $406 \mathrm{~cm}^{-1}\left(\alpha\right.$-phase [49]), $429 \mathrm{~cm}^{-1}, 906 \mathrm{~cm}^{-1}\left(\mathrm{CH}_{2}\right.$ wag absorption in $\alpha$-phase [50]), $1037 \mathrm{~cm}^{-1}, 1111 \mathrm{~cm}^{-1}$ (C-O-C stretching [43]) and $1659 \mathrm{~cm}^{-1}$ ( $\mathrm{C}=\mathrm{O}$ stretching [51]). The $\mathrm{C}=\mathrm{O}\left(1659 \mathrm{~cm}^{-1}\right)$ is perceived to be attributed to oxidized $\mathrm{CB}$ clumps as it is not observed in PVDF-HFP.

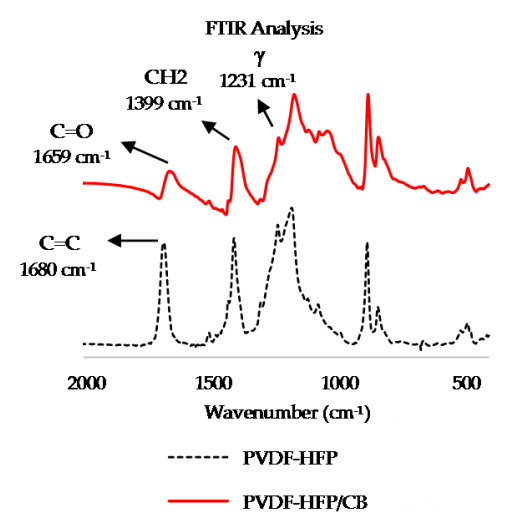

Figure 4. FTIR analysis of PVDF-HFP (in dotted black) and PVDF-HFP/CB (in solid red). 


\subsubsection{FTIR Analysis Post IR Treatment}

To evaluate the role of IR treatment in PVDF-HFP/CB composite, FTIR analyses were conducted on both PVDF-HFP and PVDF-HFP/CB before and after IR treatment. The FTIR peak of PVDF-HFP at $1680 \mathrm{~cm}^{-1}(\mathrm{C}=\mathrm{C})$ disappears after IR treatment but the FTIR peaks corresponding to $\alpha, \beta$ and $\gamma$ crystal structures of IR-treated PVDF-HFP were unchanged from FTIR peaks in untreated PVDF-HFP (Figure 5a). On the other hand, FTIR signal of the PVDF-HFP/CB composite did shift quite significantly after IR treatment (Figure 5b).

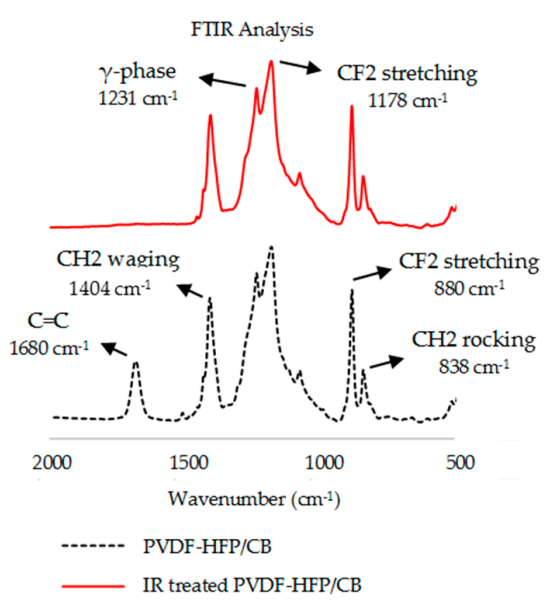

(a)

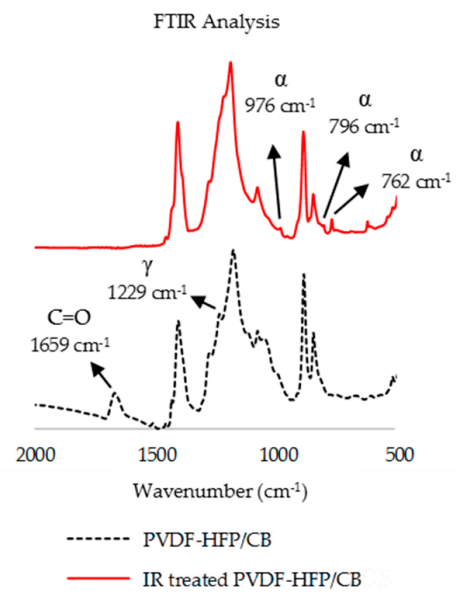

(b)

Figure 5. FTIR analysis of (a) PVDF-HFP (in dotted black) and IR treated PVDF-HFP (in solid red); (b) PVDF-HFP/CB (in dotted black) and IR treated PVDF-HFP/CB (in solid red) specifies formation of less polar alpha structures and loss of several bonds after IR treatment in presence of $C B$.

IR treatment caused the intensity of FTIR peaks to be decreased at $1037 \mathrm{~cm}^{-1}, 1111 \mathrm{~cm}^{-1}(\mathrm{C}-\mathrm{O}-\mathrm{C}$ stretching [47]), $1229 \mathrm{~cm}^{-1}, 1504 \mathrm{~cm}^{-1}\left(\mathrm{CH}_{2}\right.$ bond [52]), $1659 \mathrm{~cm}^{-1}$. The new FTIR peaks at $762 \mathrm{~cm}^{-1}$ ( $\alpha$-phase [53]), $796 \mathrm{~cm}^{-1}$ ( $\alpha$-phase [53]), $976 \mathrm{~cm}^{-1}(\alpha$-phase [53]) after IR treatment support the realization of more $\alpha$-phase structure in the composite. Spin casting of thin films elutes the PVDF-HFP polymer in a mixture of the more polar $\beta$ or $\gamma$ crystalline structure along with some $\alpha$ structure under our experimental conditions (FTIR peaks in Section 3.1.1). IR treatment transforms the film so that it has more $\alpha$ structures in the composite. Changing the polymer from the more-polar $\beta$ or $\gamma$ crystalline structure to a non-polar $\alpha$ changes the composite's adsorption properties. This is further discussed in Section 4.1.2. It was initially unexpected to the researchers that IR treatment of PVDF-HFP/CB induced a change in crystalline structure, while the same treatment of PVDF-HFP did not. However, it has been shown that heating PVDF-HFP up to melting point and cooling it slowly induces formation of $\alpha$-phase structures. It is believed that the CB particles in the composite absorb IR energy and locally heat the PVDF-HFP in the composite. Slow cooling of the CB-heated PVDF-HFP then causes the formation of $\alpha$-phase structures seen by FTIR.

\subsubsection{FTIR Analysis Post Addition of DEC}

FTIR analysis were conducted to further investigate the role of addition of DEC to PVDF-HFP and to PVDF-HFP/CB. The results are presented in Figure 6. FTIR analysis (Figure 6a) indicates that the crystalline order of PVDF-HFP is not considerably affected when DEC is added to the PVDF-HFP alone. The peaks at $483 \mathrm{~cm}^{-1}, 511 \mathrm{~cm}^{-1}, 601 \mathrm{~cm}^{-1}, 658 \mathrm{~cm}^{-1}, 838 \mathrm{~cm}^{-1}, 880 \mathrm{~cm}^{-1}, 1073 \mathrm{~cm}^{-1}$, $1178 \mathrm{~cm}^{-1}, 1405 \mathrm{~cm}^{-1}, 1429 \mathrm{~cm}^{-1}$ do not change after addition of DEC to the polymer. Not only the frequencies but also the intensities remain similar. The polymer also remains amorphous, as the peaks at $838 \mathrm{~cm}^{-1}$ and $880 \mathrm{~cm}^{-1}$ (associated with amorphous structure of the film) stay unchanged [2]. FTIR spectra for PVDF-HFP/CB and PVDF-HFP/CB after addition of DEC demonstrates noteworthy 
changes (Figure 6b). The disappearance of the peaks at $1111 \mathrm{~cm}^{-1}$ (C-O-C stretching [47]), $1504 \mathrm{~cm}^{-1}$ $\left(\mathrm{CH}_{2}\right.$ bond [52]), $1659 \mathrm{~cm}^{-1}\left(\mathrm{C}=\mathrm{O}\right.$ bond [51]) and decrease in intensity of $1299 \mathrm{~cm}^{-1}$ (mixture of $\mathrm{CF}_{2}$ stretching, $\mathrm{CC}$ stretching and $\mathrm{CH}_{2}$ rocking [54]) are detected after addition of DEC to the PVDF-HFP/CB. The most striking difference, however, is that the carbonyl bond $\left(\mathrm{C}=\mathrm{O} 1659 \mathrm{~cm}^{-1}\right)$ in PVDF-HFP/CB disappears after addition of DEC to the composite. The loss of the peak at $1659 \mathrm{~cm}^{-1}$ indicates that oxidized CB clumps are either washed away or reduced by the DEC. In either event, addition of DEC creates a more uniform film across the composite. This is believed to enhance the transduction property, which is analyzed in Section 4.2.

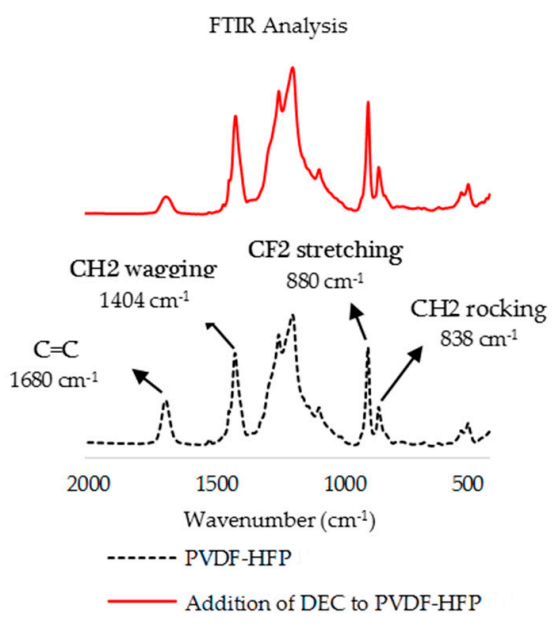

(a)

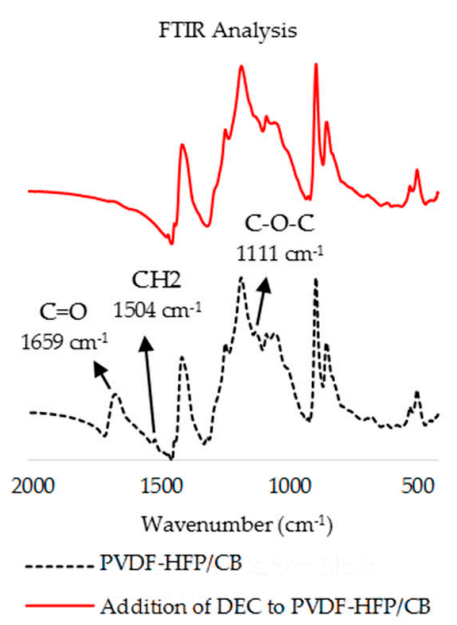

(b)

Figure 6. FTIR analysis of (a) PVDF-HFP (in dotted black) and PVDF-HFP after addition of DEC (in solid red); (b) PVDF-HFP/CB (in black) and PVDF-HFP/CB after addition of DEC (in solid red).

\section{2. $X R D$ Analysis}

The XRD patterns for PVDF-HFP, PVDF-HFP/CB and IR treated PVDF-HFP/CB are illustrated in Figure 7. The data were collected from $2 \theta=10^{\circ}$ to $50^{\circ}$ at a rate of $1^{\circ} \cdot \mathrm{s}^{-1}$. This analysis illustrates the semi-crystalline property of the PVDF-HFP. PVDF-HFP peaks are located at $19.1^{\circ}$ and $20.9^{\circ}$. PVDF-HFP/CB shows peaks at $18.4^{\circ}$ and $20.05^{\circ}$. XRD analysis also shows changes in crystal structure of PVDF-HFP/CB due to IR treatment. The peak at $20.05^{\circ}$ for PVDF-HFP/CB shifts to $19.9^{\circ}$ after IR treatment and new peaks at $17.7^{\circ}$ and $26.56^{\circ}$ are observed. This confirms the formation of $\alpha$ phase as the peaks at $17.6^{\circ}, 18.4^{\circ}$ and $26.56^{\circ}$ represent $\alpha$ phase [23]. IR treated PVDF-HFP did not show marked differences than untreated PVDF-HFP (data not shown).

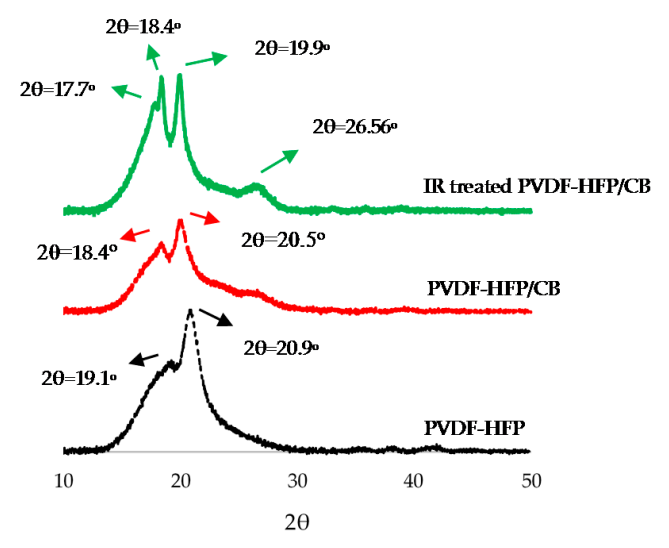

Figure 7. XRD of PVDF-HFP (in black), PVDF-HFP/CB (in red) and IR treated PVDF-HFP/CB (in green) ( $2 \theta$ between $10^{\circ}$ to $50^{\circ}$ ). 


\subsection{SEM Analysis}

SEM images of CB (black pearl 2000) and the PVDF-HFP/CB porous films are presented (Figure 8.). The CB structures is shown in Figure 8a. The CB particle size was measured and estimated to be $36 \mathrm{~nm}$. The image of a PVDF-HFP/CB composite on top of the IDE is shown in the Figure 8b. The morphology and the porous thin film structure is demonstrated. The high surface area and the micron-size pores of the thin film are illustrated in the image. This indicate the available large surface for interaction between the VOCs and the film. In addition, the micron-size pores provide space for addition of a thin polymer such as $\mathrm{PEO}$ to the composite to enhance the adsorption ability of the composite. Cross section image of the film and the pores at higher magnification are shown in the insets. The average film thickness was estimated to be $4.2 \mu \mathrm{m}$.

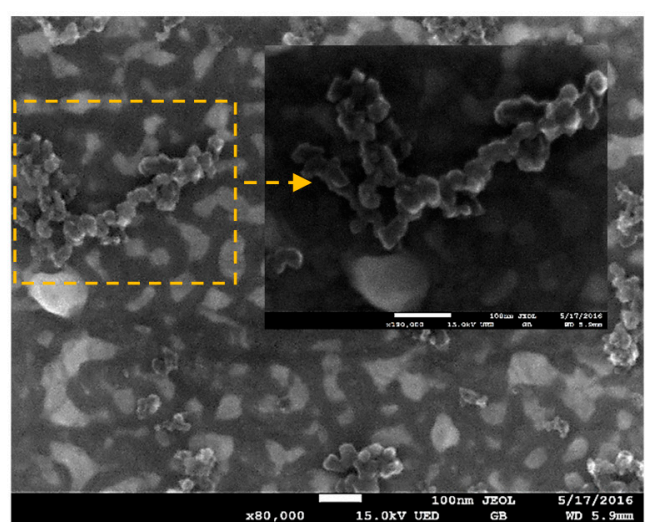

(a)

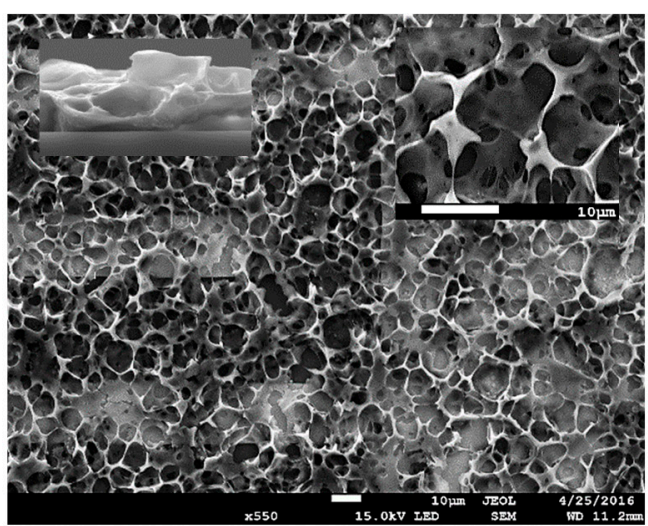

(b)

Figure 8. (a) SEM images of CB (black pearl 2000). A CB structure at higher magnitude is shown in the inset. Scale bar $100 \mathrm{~nm}$; (b) SEM image of thin PVDF-HFP/CB film on the IDE. Note the porous structure. The film cross section is shown in the inset top left. The pores at higher magnification are shown in the inset top right. Scale bar $10 \mu \mathrm{m}$.

\section{Sensor Results and Discussion}

Sensors fabricated with the methods and materials described in Section 2 were tested using the setup discussed in Section 2.4. The results from the sensors are presented and discussed in this section. For the experiments, a set of three devices were fabricated at the same batch and tested simultaneously. Results are presented in terms of relative response $(R R)$ according to the following equation:

$$
R R_{V O C}=\left(R_{V O C}-R_{\text {air }}\right) / R_{\text {air }} \times 100
$$

The presented results show the average response of the three devices with the standard deviations as error bars. Devices with and without enhancement were tested with acetone and ethanol at the same time. Sensor selectivity (SS) is defined as $R R_{\text {ethanol }}$ divided by $R R_{\text {acetone }}$ (using 2300 ppm concentration via linear regression analysis; results obtained at different concentrations are similar):

$$
S S=R R_{\text {ethanol }} / R R_{\text {acetone }}
$$

The sensing mechanism of PVDF-HFP/CB composite can be described based on percolation theory in the matrix [20]. CB particles form conducting paths in the PVDF-HFP matrix. Swelling of PVDF-HFP in response to VOCs increases the separation between CB structures and increases the sensor resistance. The transduction efficiency of the composite depends on the swelling properties of the polymer that separate two CB structures and also the distribution and uniformity of the $C B$ structures across the film. Methods to alter the adsorption ability and transduction efficiency of PVDF-HFP/CB are described in Section 2. In similar studies of sensors comprised of polymer with 
conductive filler (including CB) $[2,55,56]$, or modeling this type of sensor $[19,20]$, the polymer has been shown to play the major role.

The sensors reported on in Section 4.1 and following are a mixture of polymer and CB. To better understand the contribution of $\mathrm{CB}$, sensors of $\mathrm{CB}$ alone were fabricated and tested using VOCs and dry air. A sensor was built by drop-casting CB (without PVDF-HFP) onto an IDE and exposing it in turn to a VOC followed by dry air. The results are shown in Figure 9. CB resistivity decreases due to exposure to water vapor, ethanol and acetone and does not fully return to pre-exposure levels. For water vapor, equilibrium is reached after $2 \mathrm{~h}(7200 \mathrm{~s})$. For ethanol and acetone, the long-term effect is also present. Sensors with CB incorporated into a PVDF-HFP polymer may exhibit a similar negative drift when exposed to ethanol or acetone. On the other hand, swelling of PVDF-HFP when exposed to ethanol or acetone causes an increase in resistance. Effects of incomplete desorption of VOCs from PVDF-HFP would likely cause a positive baseline drift.

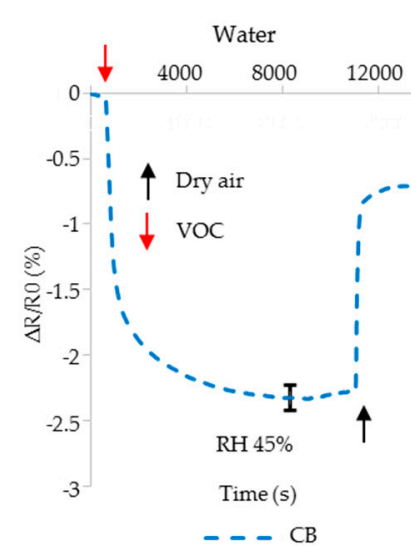

(a)

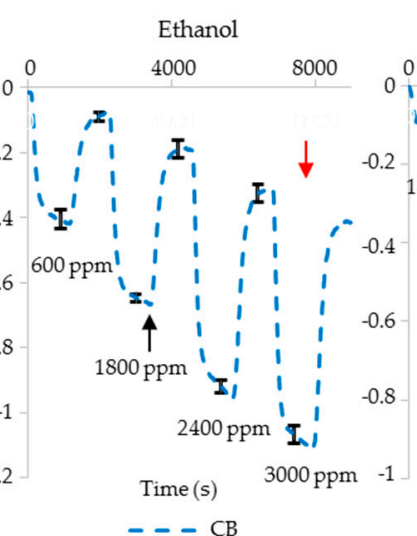

(b)

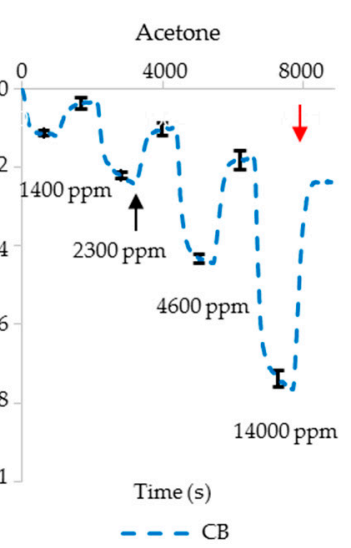

(c)

Figure 9. Resistance change of the CB sensors as they are exposed to (a) water vapor with $\mathrm{RH} 45 \%$; various concentration of $(\mathbf{b})$ ethanol and $(\mathbf{c})$ acetone.

\subsection{Method I}

Adsorption properties of the film are altered by addition of a thin PEO layer on the composite or through IR treatment of the film. In both cases the ability of the composite to adsorb acetone or ethanol are altered.

\subsubsection{Addition of a PEO Layer on the Film}

The PEO, dissolved in water, was cast onto the film as described in the Methods section. The addition of PEO layer on the film alters the adsorption of both ethanol and acetone to the composite. QCM analysis was conducted to confirm and estimate the mass of PEO. There is a linear relation between the frequency of QCM and the mass of the material for thin films [55]. QCM frequency was measured before and after addition of PEO layer. Addition of PEO layer on the PVDF-HFP/CB dropped the frequency by $1003 \mathrm{~Hz}$, corresponding to 3.4\% mass of PVDF-HFP. The film was analyzed by XRD analysis both before and after addition of PEO, with no change in crystal structure observed. Resistance studies before and after addition of PEO layer to the PVDF-HFP/CB show that addition of PEO layer does not alter the sensor's resistance (percent change in resistance $<1.0 \%$ ). XRD and resistance studies both confirm that PEO does not incorporate into the composite film, but likely attaches to the surface as a thin layer, which is supported by QCM analysis. This is likely because PEO has a tendency to attach to hydrophobic materials such as PVDF-HFP [57]. It can also attach to the surface of $\mathrm{CB}$. PEO has a low glass transition temperature $\left(-67^{\circ} \mathrm{C}\right)$ which offers a fast response to a VOC. This thin layer of PEO on the surface of PVDF-HFP/CB is used to enhance the adsorption of VOCs. The response of the sensors with and without the thin PEO layer are studied for different 
concentrations of acetone and ethanol (Figure 10). Addition of PEO layer results in enhancement of the sensor's relative response to both acetone and ethanol. The enhancement relative to untreated composite varies from $62 \%$ to $68 \%$ for various concentration of ethanol. The enhancement is lower for acetone than ethanol ( $22 \%$ to $30 \%$ ). The $S S$ for the untreated sensors is 0.63 but increases to 0.83 after addition of PEO layer on PVDF-HFP/CB $\left(S S_{\mathrm{ORIG}}=0.63 ; S S_{\mathrm{PEO}}=0.83\right)$. The significant change in cross-selective enhancement is a powerful tool for building VOC-selective sensors. It is noted that the sensors exposed to ethanol experience slight increased positive baseline drift after addition of PEO. According to the sensing mechanism described above, VOCs trapped in PVDF-HFP and not fully released would cause the sensor resistance to exhibit a positive baseline drift. PEO interacts with ethanol to form a unique crystalline structure [58]. This likely causes incomplete ethanol desorption and thus enhanced positive drift after addition of PEO.

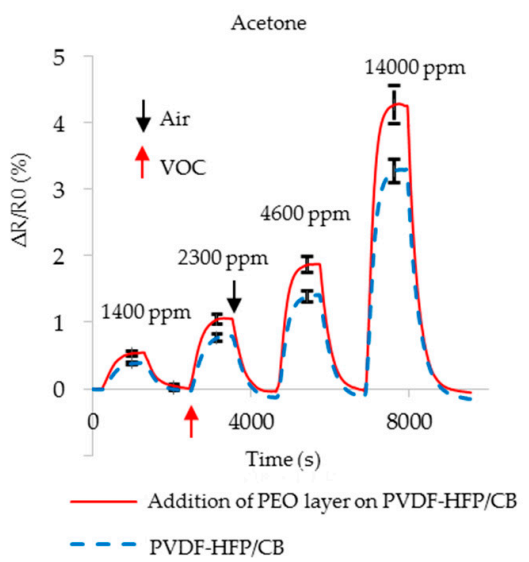

(a)

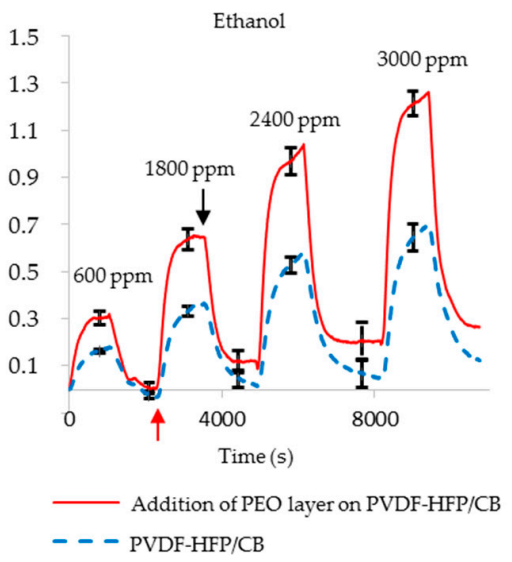

(b)

Figure 10. Resistance change of the PVDF-HFP/CB sensors with PEO layer (red solid) and without PEO layer (blue dotted) as they are exposed to various concentration of (a) acetone; (b) ethanol.

\subsubsection{IR Treatment}

IR treatment increases the amount of $\alpha$ structures in PVDF-HFP/CB as shown in Section 3.1.2. This decreases the polarity of the composite. The decrease in polarity of the film reduces its strength in adsorbing more polar VOCs. Here, the composite's capacity to detect more polar ethanol is decreased. The sensors are exposed to the various concentrations of acetone and ethanol in $45 \%$ RH humid air, and the results are shown in Figure 11.

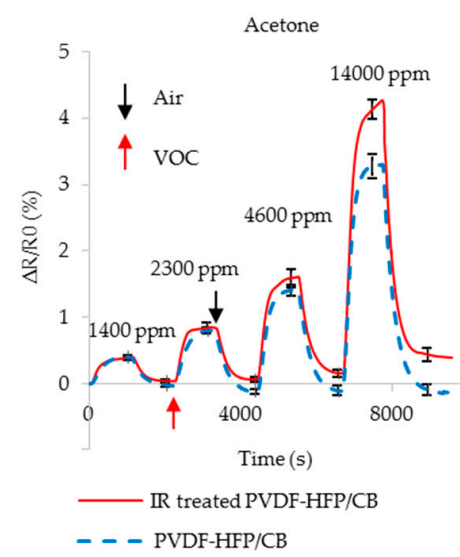

(a)

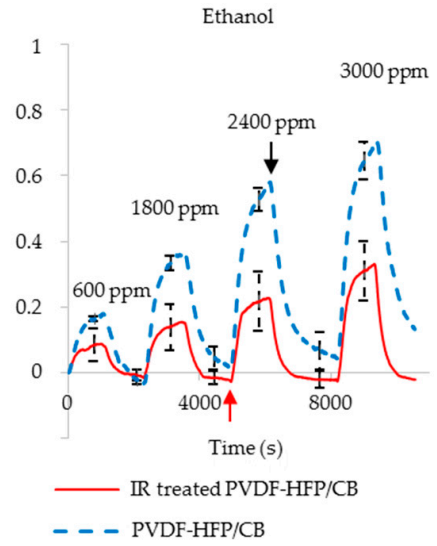

(b)

Figure 11. Resistance change of the IR treated (red solid) and non-treated (blue dotted) PVDF-HFP/CB sensors due to the exposure to various concentration of (a) acetone; (b) ethanol. 
The maximum resistance change in each cycle for acetone is similar for both before and after IR treatment. However, the sensor's relative responses is decreased up to $57 \%$ for ethanol. In addition, the slight positive drift observed before IR treatment is replaced with a slight negative drift, likely due to $\mathrm{CB} /$ ethanol interactions similar to those observed in Figure 9b. This treatment provides a second and opposite method to enhance cross-selectivity. IR treated film adsorbs less ethanol than untreated film. This causes the IR treated film to swell less than untreated film which results in a smaller resistance change. As the result, $S S_{I R}$ decreases to 0.32 .

\subsection{Method II}

DEC is added to the films in order to redistribute $C B$ more uniformly throughout the PVDF-HFP/CB composite, thereby seeking to increase transduction efficiency. FTIR analysis of PVDF-HFP/CB after addition of DEC suggested a decrease in CB clusters (Section 3.1.3). As PEO enhances cross-selectivity, $\mathrm{PEO} / \mathrm{DEC}$ was also added to the films for an enhanced cross-selective response. Resistance studies before and after addition of DEC demonstrated that addition of DEC to the film decreases the initial resistance of the sensors up to $61 \%$. The decrease in carbon clustering and decrease in initial resistance suggest the formation of a more uniform composite. Breaking down bigger clusters of CB to smaller structures increases the average contact of PVDF-HFP and CB. This enhances the transduction efficiency and sensor sensitivity to both acetone and ethanol.

To show the enhancement the relative response of PVDF-HFB/CB after addition of PEO/DEC to the composite is compared to the system after addition of DEC alone (Figure 12). As expected, upon addition of DEC alone, both films offer a higher sensor response to acetone (up to $73 \%$ better than original PVDF-HFP/CB film) and ethanol (up to 74\%). Addition of PEO/DEC to the film further enhances the transduction efficiency and sensor's sensitivity to ethanol (up to 197\% over PVDF-HFP/CB) while displaying only a modest further enhancement to acetone (up to $89 \%$ ). These modifications lead to $S S_{\mathrm{DEC}}=0.89$ and $S S_{\mathrm{PEO} / \mathrm{DEC}}=1.74$. Thus, the modifications to both adsorption capability (addition of PEO alone, $S S_{\mathrm{PEO}}=0.83$ ) and improvement in transduction efficiency (addition of DEC alone, $S S_{\mathrm{DEC}}=0.89$ ) appear to be cumulative (addition of PEO and DEC, $S S_{\mathrm{PEO} / \mathrm{DEC}}=1.74$ ). This shows addition of PEO/DEC to the film not only increases the sensitivity but also improves the sensors' cross-selectivity when used with addition of DEC to the film. The higher change in resistance also suggests that the use of $\mathrm{PEO}$ and DEC potentially transforms CB particles into a $\mathrm{PEO} / \mathrm{CB}$ composite. Swelling of $\mathrm{PEO}$ increases the separation between $\mathrm{CB}$ particles which increases the resistivity of $\mathrm{PEO} / \mathrm{CB}$ composites. This increases the sensitivity of the film and also enhances the cross-selectivity of system.

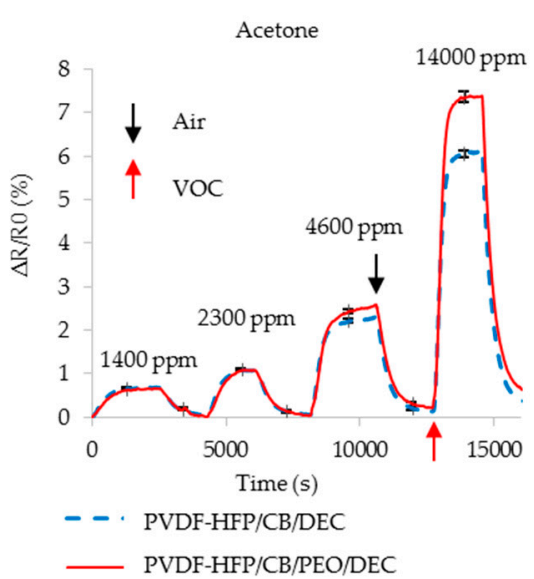

(a)

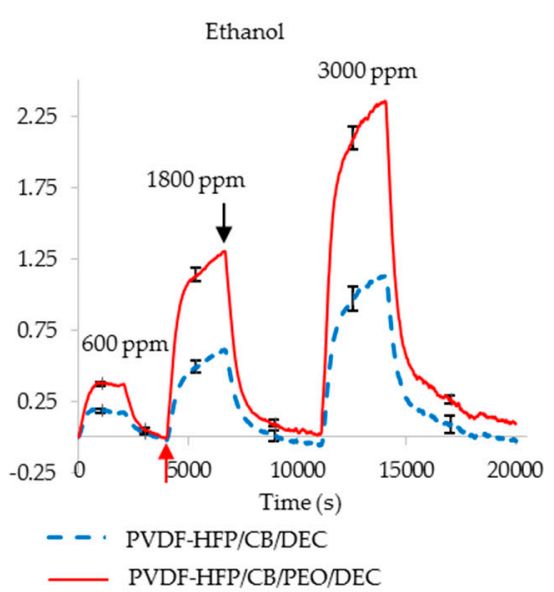

(b)

Figure 12. Resistance change of PVDF-HFP/CB film after addition of DEC (dotted blue) is compared with addition of PEO/DEC (solid red) at various concentration of (a) acetone; (b) ethanol. 


\subsection{Sensor Degradation}

To study the degradation of the composite materials, five sensors of PVDF-HFP/CB were fabricated and tested over a 25 day periodically. The sensors were stored in ambient air. The sensors were tested for their response using synthetic air with humidity of $45 \% \mathrm{RH}$. The standard deviation $(\sigma)$ of the sensors' resistance before and after exposure was less than $1.1 \%$ of initial resistance, indicating a good stability of the PVDF-HFP/CB composite material. No decreasing or increasing pattern in the sensor's initial resistance and sensors' response was observed over this period. Acetone was the VOC used for these tests, but a similarly robust result would be expected from ethanol or any other VOC. The excellent stability is believed to be due to hydrophobic properties of PVDF-HFP that prevent moisture absorption, and the high stability of the materials against oxygen, nitrogen, and carbon dioxide.

\section{Conclusions}

Two methods for cross-selectivity enhancement of porous thin PVDF-HFP/CB film based sensors for acetone and ethanol have been presented and discussed. The first method, method I, uses techniques to alter the adsorption properties of the sensor film. These techniques included addition of a layer of PEO to improve the adsorptions of ethanol and IR treatment of the film to reduce the sensitivity to ethanol. It is interesting that IR treatment of PVDF-HFP had no effect on the crystal structure of the PVDF-HFP, while IR treatment of PVDF-HFP/CB did cause a change in the crystal structure of the PVDF-HFP. It is suggested that the IR treatment caused localized heating of the CB particles, which subsequently cooled over time. Slow cooling of heated PVDF-HFP (5\%) has been shown to favor formation of alpha phase [39]. This resulted in an enhanced cross-selectivity of ethanol and acetone. Addition of PEO layer increased the sensors relative response by up to $30 \%$ for acetone and $68 \%$ for ethanol. In terms of selectivity, this led to $S S_{\text {ORIG }}=0.63$ and $S S_{\text {PEO }}=0.83$. IR treatment did not significantly affect acetone response, and it reduced the ethanol relative response by up to $57 \%$ leading to $S S_{\text {IR }}=0.32$. The second method, method II, uses techniques to improve the electrical transduction efficiency of the sensor film. Addition of DEC or PEO/DEC enhanced the transduction properties across the board but also, for $\mathrm{PEO} / \mathrm{DEC}$, significantly increased selectivity; $S S_{\mathrm{DEC}}=0.89$ and $S S_{\mathrm{PEO} / \mathrm{DEC}}=1.74$. These modifications altered sensor selectivity from 0.32 to 1.74 . The fabrication methods and characterization results for the sensors have been presented and discussed. The sensors were tested with various concentrations of ethanol and acetone in $45 \% \mathrm{RH}$ humid air at $22{ }^{\circ} \mathrm{C}$, thereby mimicking typical environmental conditions. The presented methods can be utilized in a single film with multiple IDEs to realize a cross-selective sensor array for ethanol and acetone in the presence of high humidity applications.

Acknowledgments: This material is based upon work supported by the National Science Foundation (NSF) under Grant No. 1502310. Acknowledgments are also due to the Integrated Nanosystems Development Institute (INDI) for providing the facilities for this research, including the JEOL7800F Field Emission Scanning Electron Microscope awarded through NSF Grant MRI-1229514 and Bruker X-Ray Diffraction System awarded through NSF Grant MRI-1429241. The authors would like to thank Jenna Munshi and Clara Reasoner for their assistance in concentration measurement using GC/MS, Ibrahim Mohmoh for his assistance in conducting the experiments for sensor degradation, Nojan Aliahmad for his assistance with the SEM instrument. A.D. would also like to thank Craig Brodie for his assistance with proofreading.

Author Contributions: M.A. directed, conceived, and designed the experiments; A.D. performed the experiments; A.D., S.S. and A.S. analyzed the data; K.V. contributed reagents/materials/analysis tools; all authors contributed in writing the paper.

Conflicts of Interest: The authors declare no conflict of interest.

\section{References}

1. Kunstmann-Olsen, C.; Belić, D.; Bradley, D.F.; Grzelczak, M.P.; Brust, M. Humidity-dependent reversible transitions in gold nanoparticle superlattices. Chem. Mater. 2016, 28, 2970-2980. [CrossRef]

2. Daneshkhah, A.; Shrestha, S.; Agarwal, M.; Varahramyan, K. Poly(vinylidene fluoride-hexafluoropropylene) composite sensors for volatile organic compounds detection in breath. Sens. Actuators B Chem. 2015, 221, 635-643. [CrossRef] 
3. Agarwal, M.; Balachandran, M.D.; Shrestha, S.; Varahramyan, $\mathrm{K} . \mathrm{SnO}_{2}$ nanoparticle-based passive capacitive sensor for ethylene detection. J. Nanomater. 2012, 2012, 145406. [CrossRef]

4. Meng, F.-L.; Guo, Z.; Huang, X.-J. Graphene-based hybrids for chemiresistive gas sensors. TrAC Trends Anal. Chem. 2015, 68, 37-47. [CrossRef]

5. Cao, Q.; Rogers, J.A. Ultrathin films of single-walled carbon nanotubes for electronics and sensors: A review of fundamental and applied aspects. Adv. Mater. 2009, 21, 29-53. [CrossRef]

6. Sinha, N.; Ma, J.; Yeow, J.T.W. Carbon nanotube-based sensors. J. Nanosci. Nanotechnol. 2006, 6, 573-590. [CrossRef] [PubMed]

7. Yoon, H.J.; Jun, D.H.; Yang, J.H.; Zhou, Z.; Yang, S.S.; Cheng, M.M.-C. Carbon dioxide gas sensor using a graphene sheet. Sens. Actuators B Chem. 2011, 157, 310-313. [CrossRef]

8. Lin, Z.D.; Young, S.J.; Chang, S.J. $\mathrm{CO}_{2}$ gas sensors based on carbon nanotube thin films using a simple transfer method on flexible substrate. IEEE Sens. J. 2015, 15, 7017-7020. [CrossRef]

9. Wang, L.; Shi, X.; Kariuki, N.N.; Schadt, M.; Wang, G.R.; Rendeng, Q.; Choi, J.; Luo, J.; Lu, S.; Zhong, C.-J. Array of molecularly mediated thin film assemblies of nanoparticles: Correlation of vapor sensing with interparticle spatial properties. J. Am. Chem. Soc. 2007, 129, 2161-2170. [CrossRef] [PubMed]

10. Huang, J.; Wan, Q. Gas sensors based on semiconducting metal oxide one-dimensional nanostructures. ResearchGate 2009, 9, 9903-9924. [CrossRef] [PubMed]

11. Fine, G.F.; Cavanagh, L.M.; Afonja, A.; Binions, R. Metal oxide semi-conductor gas sensors in environmental monitoring. Sensors 2010, 10, 5469-5502. [CrossRef] [PubMed]

12. Cooper, J.S.; Raguse, B.; Chow, E.; Hubble, L.; Müller, K.-H.; Wieczorek, L. Gold nanoparticle chemiresistor sensor array that differentiates between hydrocarbon fuels dissolved in artificial seawater. Anal. Chem. 2010, 82, 3788-3795. [CrossRef] [PubMed]

13. Garg, N.; Mohanty, A.; Lazarus, N.; Schultz, L.; Rozzi, T.R.; Santhanam, S.; Weiss, L.; Snyder, J.L.; Fedder, G.K.; Jin, R. Robust gold nanoparticles stabilized by trithiol for application in chemiresistive sensors. Nanotechnology 2010, 21, 405501. [CrossRef] [PubMed]

14. Song, E.; Choi, J.-W. Conducting polyaniline nanowire and its applications in chemiresistive sensing. Nanomaterials 2013, 3, 498-523. [CrossRef]

15. Marchesi, L.F.Q.P.; Simões, F.R.; Pocrifka, L.A.; Pereira, E.C. Investigation of polypyrrole degradation using electrochemical impedance spectroscopy. J. Phys. Chem. B 2011, 115, 9570-9575. [CrossRef] [PubMed]

16. Kim, Y.S.; Ha, S.-C.; Yang, Y.; Kim, Y.J.; Cho, S.M.; Yang, H.; Kim, Y.T. Portable electronic nose system based on the carbon black-polymer composite sensor array. Sens. Actuators B Chem. 2005, 108, 285-291. [CrossRef]

17. Ashwini, N.; Mallya, R.K. Conducting polymer-carbon black nanocomposite sensor for volatile organic compounds and correlating sensor response by molecular dynamics. Sens. Actuators B Chem. 2014, 201, 308-320.

18. Chatterjee, S.; Castro, M.; Feller, J.F. An e-nose made of carbon nanotube based quantum resistive sensors for the detection of eighteen polar/nonpolar VOC biomarkers of lung cancer. J. Mater. Chem. B 2013, 1, 4563-4575. [CrossRef]

19. Lei, H.; Pitt, W.G.; McGrath, L.K.; Ho, C.K. Modeling carbon-black/polymer composite sensors. Sens. Actuators B Chem. 2007, 125, 396-407. [CrossRef] [PubMed]

20. Xu, H.P.; Wu, Y.H.; Yang, D.D.; Wang, J.R.; Xie, Q.H. Study on theories and influence factors of PTC property in polymer-based conductive composites. Adv. Mater. Sci. 2011, 27, 173-183.

21. Gurarslan, A.; Yu, Y.; Su, L.; Yu, Y.; Suarez, F.; Yao, S.; Zhu, Y.; Ozturk, M.; Zhang, Y.; Cao, L. Surface-energyassisted perfect transfer of centimeter-scale monolayer and few-layer $\mathrm{MoS}_{2}$ films onto arbitrary substrates. ACS Nano 2014, 8, 11522-11528. [CrossRef] [PubMed]

22. Salvatore, G.A.; Münzenrieder, N.; Barraud, C.; Petti, L.; Zysset, C.; Büthe, L.; Ensslin, K.; Tröster, G. Fabrication and transfer of flexible few-layers $\mathrm{MoS}_{2}$ thin film transistors to any arbitrary substrate. ACS Nano 2013, 7, 8809-8815. [CrossRef] [PubMed]

23. Martins, P.; Lopes, A.C.; Lanceros-Mendez, S. Electroactive phases of poly(vinylidene fluoride): Determination, processing and applications. Prog. Polym. Sci. 2014, 39, 683-706. [CrossRef]

24. Lonergan, M.C.; Severin, E.J.; Doleman, B.J.; Beaber, S.A.; Grubbs, R.H.; Lewis, N.S. Array-based vapor sensing using chemically sensitive, carbon black-polymer resistors. Chem. Mater. 1996, 8, 2298-2312. [CrossRef]

25. Kumar, B.; Castro, M.; Feller, J.-F. Quantum resistive vapour sensors made of polymer coated carbon nanotubes random networks for biomarkers detection. Chem. Sens. 2013, 3, 20. 
26. Pandis, C.; Peoglos, V.; Kyritsis, A.; Pissis, P. Gas sensing properties of conductive polymer nanocomposites. Procedia Eng. 2011, 25, 243-246. [CrossRef]

27. Tapnurat, M.; Choopun, S.; Gardchareon, A.; Singjai, P.; Mangkorntong, P.; Mangkorntong, N. Thick film of carbon nanotube composite for ethanol sensor. J. Spec. Issue Nanotechnol. 2005, 4, 21-25.

28. Lai, Y.-T.; Kuo, J.-C.; Yang, Y.-J. A novel gas sensor using polymer-dispersed liquid crystal doped with carbon nanotubes. Sens. Actuators A Phys. 2013, 215, 83-88. [CrossRef]

29. Robinson, J.A.; Snow, E.S.; Bădescu, Ş.C.; Reinecke, T.L.; Perkins, F.K. Role of defects in single-walled carbon nanotube chemical sensors. Nano Lett. 2006, 6, 1747-1751. [CrossRef] [PubMed]

30. Olejnik, R.; Slobodian, P.; Riha, P.; Saha, P. Selectivity of multi-wall carbon nanotube network sensoric units to ethanol vapors achieved by carbon nanotube oxidation. J. Mater. Sci. Res. 2012, 1, 101-106. [CrossRef]

31. Sin, M.L.Y.; Chow, G.C.T.; Li, W.J.; Leong, P.; Wong, M.K.; Wong, K.W.; Lee, T. Chemically functionalized multi-walled carbon nanotube sensors for ultra-low-power alcohol vapor detection. In Proceedings of the Sixth IEEE Conference on Nanotechnology, Cincinnati, OH, USA, 17-20 July 2006; Volume 2, pp. 461-464.

32. Fu, K.; Chen, S.; Zhao, J.; Willis, B.G. Dielectrophoretic assembly of gold nanoparticles in nanoscale junctions for rapid, miniature chemiresistor vapor sensors. ACS Sens. 2016, 1, 444-450. [CrossRef]

33. Chaing, H.-S. Thermodynamics of Benzene Sorption in Polyethylene Oxide. Ph.D. Thesis, Texas Tech University, Lubbock, TX, USA, 1977.

34. Xie, H.; Yang, Q.; Sun, X.; Yang, J.; Huang, Y. Gas sensor arrays based on polymer-carbon black to detect organic vapors at low concentration. Sens. Actuators B Chem. 2006, 113, 887-891. [CrossRef]

35. Marra, J.; Hair, M.L. Interactions between two adsorbed layers of poly(ethylene oxide)/polystyrene diblock copolymers in heptane-Toluene mixtures. Colloids Surf. 1988, 34, 215-226. [CrossRef]

36. Aliahmad, N.; Shrestha, S.; Varahramyan, K.; Agarwal, M. Poly(vinylidene fluoride-hexafluoropropylene) polymer electrolyte for paper-based and flexible battery applications. AIP Adv. 2016, 6, 065206. [CrossRef]

37. Shimizu, H.; Arioka, Y.; Ogawa, M.; Wada, R.; Okabe, M. Sol-gel transitions of poly(vinylidene fluoride) in organic solvents containing $\mathrm{LiBF}_{4}$. Polym. J. 2011, 43, 540-544. [CrossRef]

38. Reiteration of Existing OSHA Policy on Indoor Air Quality: Office Temperature/Humidity and Environmental Tobacco Smoke. Occupational Safety and Health Administration. Available online: https:/ /www.osha.gov/pls/ oshaweb/owadisp.show_document?p_table=INTERPRETATIONS\&p_id=24602 (accessed on 9 November 2016).

39. Jayasuriya, A.C.; Schirokauer, A.; Scheinbeim, J.I. Crystal-structure dependence of electroactive properties in differently prepared poly(vinylidene fluoride/hexafluoropropylene) copolymer films. J. Polym. Sci. Part B Polym. Phys. 2001, 39, 2793-2799. [CrossRef]

40. Srivastava, H.; Lade, H.; Paul, D.; Arthanareeswaran, G.; Kweon, J.H. Styrene-based copolymer for polymer membrane modifications. Appl. Sci. 2016, 6, 159. [CrossRef]

41. Batth, A.; Mueller, A.; Rakesh, L.; Mellinger, A. Electrical properties of poly(vinylidene fluoridehexafluoropropylene) (PVDF-HFP) blended with carbon nanotubes. In Proceedings of the 2012 Annual Report Conference on Electrical Insulation and Dielectric Phenomena (CEIDP), Montreal, QC, Canada, 14-17 October 2012; pp. 28-31.

42. Saikia, D.; Kumar, A. Ionic conduction in P(VDF-HFP)/PVDF-(PC + DEC)-LiClO 4 polymer gel electrolytes. Electrochim. Acta 2004, 49, 2581-2589. [CrossRef]

43. Ataollahi, N.; Ahmad, A.; Hamzah, H.; Rahman, M.Y.A.; Mohamed, N.S. Ionic conductivity of PVDF-HFP/MG49 based solid polymer electrolyte. Adv. Mater. Res. 2012, 501, 29-33. [CrossRef]

44. Sim, L.N.; Majid, S.R.; Arof, A.K. FTIR studies of PEMA/PVdF-HFP blend polymer electrolyte system incorporated with $\mathrm{LiCF}_{3} \mathrm{SO}_{3}$ salt. Vib. Spectrosc. 2012, 58, 57-66. [CrossRef]

45. Zeng, Z.; Yu, D.; He, Z.; Liu, J.; Xiao, F.-X.; Zhang, Y.; Wang, R.; Bhattacharyya, D.; Tan, T.T.Y. Graphene oxide quantum dots covalently functionalized PVDF membrane with significantly-enhanced bactericidal and antibiofouling performances. Sci. Rep. 2016, 6, 20142. [CrossRef] [PubMed]

46. Peng, G.; Zhao, X.; Zhan, Z.; Ci, S.; Wang, Q.; Liang, Y.; Zhao, M. New crystal structure and discharge efficiency of poly(vinylidene fluoride-hexafluoropropylene)/poly(methyl methacrylate) blend films. RSC Adv. 2014, 4, 16849-16854. [CrossRef]

47. Bai, H.; Wang, X.; Zhou, Y.; Zhang, L. Preparation and characterization of poly(vinylidene fluoride) composite membranes blended with nano-crystalline cellulose. Prog. Nat. Sci. Mater. Int. 2012, 22, 250-257. [CrossRef] 
48. Rana, D.S.; Chaturvedi, D.K.; Quamara, J.K. Morphology, crystalline structure, and chemical properties of $100 \mathrm{MeV}$ Ag-ion beam irradiated polyvinylidene fluoride (PVDF) thin film. J. Optoelectron. Adv. Mater. 2009, 11, 705-712.

49. Silva, A.B.; Wisniewski, C.; Esteves, J.V.A.; Gregorio, R.G., Jr. Effect of drawing on the crystal-amorphous interphase, remanent polarization and dielectric properties of $\alpha$-PVDF Films. Ferroelectrics 2011, 413, 220-230. [CrossRef]

50. Svatos, A.; Attygalle, A.B. Characterization of vinyl-substituted, carbon-carbon double bonds by GC/FT-IR analysis. Anal. Chem. 1997, 69, 1827-1836. [CrossRef] [PubMed]

51. Chen, M.; Zeng, H.; Larkum, A.W.D.; Cai, Z.-L. Raman properties of chlorophyll d, the major pigment of Acaryochloris marina: Studies using both Raman spectroscopy and density functional theory. Spectrochim. Acta A Mol. Biomol. Spectrosc. 2004, 60, 527-534. [CrossRef]

52. Prasad, S.G.; De, A.; De, U. Structural and optical investigations of radiation damage in transparent PET Polymer films. Int. J. Spectrosc. 2011, 2011, 810936. [CrossRef]

53. Vasundhara, K.; Mandal, B.P.; Tyagi, A.K. Enhancement of dielectric permittivity and ferroelectricity of a modified cobalt nanoparticle and polyvinylidene fluoride based composite. RSC Adv. 2015, 5, 8591-8597. [CrossRef]

54. Nallasamy, P.; Mohan, S. Vibrational spectroscopic characterization of form II poly(vinylidene fluoride). Indian J. Pure Appl. Phys. IJPAP 2005, 43, 821-827.

55. Daneshkhah, A.; Shrestha, S.; Agarwal, M.; Varahramyan, K. PPy/PMMA/PEG-based sensor for lowconcentration acetone detection. In Proceedings of the SPIE 9107, Smart Biomedical and Physiological Sensor Technology XI, Baltimore, WD, USA, 7-9 May 2014; Volume 9107. ID 910712.

56. Bai, H.; Shi, G. Gas Sensors Based on Conducting Polymers. Sensors 2007, 7, 267-307. [CrossRef]

57. Prabakaran, K.; Mohanty, S.; Nayak, S.K. PEO/PVdF-HFP electrolytes for natural dye sensitized solar cell applications: Effect of modified nano- $\mathrm{TiO}_{2}$ on electrochemical and photovoltaic performance. J. Mater. Sci. Mater. Electron. 2015, 26, 3887-38971. [CrossRef]

58. Ho, D.L.; Hammouda, B.; Kline, S.R.; Chen, W.-R. Unusual phase behavior in mixtures of poly(ethylene oxide) and ethyl alcohol. J. Polym. Sci. Part B Polym. Phys. 2006, 44, 557-564. [CrossRef]

(C) 2017 by the authors. Licensee MDPI, Basel, Switzerland. This article is an open access article distributed under the terms and conditions of the Creative Commons Attribution (CC BY) license (http:/ / creativecommons.org/licenses/by/4.0/). 